\title{
Kinetics of the fcc $\rightarrow$ hcp Phase Transformation in Cu-Ge Solid Solutions Upon Isothermal Aging
}

\author{
E. POLATIDIS, N. ZOTOV, E. BISCHOFF, and E.J. MITTEMEIJER
}

\begin{abstract}
The kinetics of the $\zeta$-phase formation from a supersaturated $\alpha-\mathrm{Cu}(\mathrm{Ge})$ solid solution (i.e., transformation from the fcc crystal structure to the hep crystal structure) containing 10.8 at. pct Ge [at isothermal temperatures of $573 \mathrm{~K}, 613 \mathrm{~K}$, and $653 \mathrm{~K}\left(300{ }^{\circ} \mathrm{C}, 340{ }^{\circ} \mathrm{C}\right.$, and $\left.380{ }^{\circ} \mathrm{C}\right)$ ] were studied by X-ray diffraction (XRD) for phase fraction determination. Both in situ and ex situ annealing experiments were performed. The transformation kinetics were modeled on the basis of a versatile modular model. The transformation kinetics complied with a site-saturation nucleation mode and strongly anisotropic interface-controlled growth mode in association with a corresponding impingement mode: diffusion of Ge (towards the stacking faults, SFs) does not control the transformation rate. Transmission electron microscopy (TEM) investigations showed that segregation of Ge at the stacking faults (SFs) takes place (relatively fast) prior to the structural transformation ( $\mathrm{fcc} \rightarrow \mathrm{hcp}$ ).
\end{abstract}

DOI: $10.1007 / \mathrm{s} 11661-017-4319-\mathrm{z}$

(C) The Author(s) 2017. This article is an open access publication

\section{INTRODUCTION}

IN the $\mathrm{Cu}-\mathrm{Ge}$ and $\mathrm{Cu}-\mathrm{Si}$ systems, an $\mathrm{fcc} \rightarrow$ hcp phase transformation (i.e., starting from supersaturated $\alpha-\mathrm{Cu}(\mathrm{Ge})$ and $\alpha-\mathrm{Cu}(\mathrm{Si})$ solid solutions) can take place upon isothermal annealing ${ }^{[1-3]}$ and/or deformation. ${ }^{[1]}$ In the $\mathrm{Cu}(\mathrm{Ge})$ system, the hop product phase is called $\zeta$-phase. The precipitation of the $\zeta$-phase from supersaturated $\mathrm{Cu}(\mathrm{Ge})$ solid solutions complies with the same crystallographic orientation relationship as holds for the $\mathrm{fcc} \rightarrow \mathrm{hcp}$ phase transformations observed in $\mathrm{Co}$, Ag-Al, etc., i.e., $(11 \overline{1}) \alpha / /(0001) \zeta,[\overline{1} 10] \alpha / /[11 \overline{2} 0] \zeta{ }^{[1,2,4-6]}$

In contrast with the allotropic fcc $\rightarrow$ hcp phase transformation occurring in $\mathrm{Co},{ }^{7]}$ the transformation in the $\mathrm{Cu}-\mathrm{Ge}$ system is associated with compositional changes ${ }^{[1,8]}$ (cf. Figure 1) and therefore the transformation mechanism is an intermediate class of a diffusionless, displacive, martensitic fcc $\rightarrow$ hcp phase transformation and a diffusional phase transformation: Ge must diffuse to the $\zeta$-phase nucleation sites and/or the growing $\zeta$-phase plates to establish the $\zeta$-phase composition.

E. POLATIDIS is with the Max Planck Institute for Intelligent Systems, 70569 Stuttgart, Germany, and also with the Paul Scherrer Institute, 5232, Villigen PSI, Switzerland. Contact e-mails: e.polatidis@is.mpg.de, efthymios.polatidis@psi.ch N. ZOTOV and E.J. MITTEMEIJER are with the Max Planck Institute for Intelligent Systems and also with Institute for Materials Science, University of Stuttgart, 70569 Stuttgart, Germany. E. BISCHOFF is with the Max Planck Institute for Intelligent Systems.

Manuscript submitted March 3, 2017.

Article published online September 25, 2017
Previous transmission electron microscopy (TEM) studies on supersaturated $\mathrm{Cu}-\mathrm{Ge}$ alloys (prior to precipitation of $\zeta$-phase) showed that the principal lattice defects are intrinsic stacking faults (SFs) bound by Shockley partial dislocations. ${ }^{[9]}$ Segregation of Ge to SFs could not be shown by analytical techniques (e.g., energy-dispersive X-ray spectroscopy), but Ge segregation was indirectly indicated from the emergence of diffuse scattering in XRD patterns (between the $111_{\alpha}$ and $101_{\zeta}$ reflections). ${ }^{[1]}$

In the $\mathrm{Al}-\mathrm{Ag}$ system, the $\mathrm{fcc} \rightarrow \mathrm{hcp}$ phase transformation generally requires a larger compositional change (the hep plates consist of $\sim 60$ at. pct Ag). ${ }^{[10,11]}$ Growth of the product plates by "lengthening" was observed to occur with relatively fast speeds, as a result of dislocation glide, and by "thickening" with a 200-times slower speed, as a result of dislocation climb. It was suggested for the Al-Ag system that the kinetics are controlled by the interface motion (by a ledge mechanism) rather than by volume diffusion. ${ }^{[12]}$

More complicated mechanisms have been suggested for the formation of the hcp $\kappa$-phase in the $\mathrm{Cu}(\mathrm{Si})$ system: the $\kappa$-phase was suggested to form from bundles of SFs, developed by cooling-induced stresses, which became enriched with silicon due to short-range diffusion and "thicken," to a limited extent, on the basis of the ledge mechanism; no evidence of the lengthening mechanism was provided. ${ }^{[13]}$

In view of the above discussion, the present study was devised to elucidate in a quantitative way the kinetics of the fcc $\rightarrow$ hcp phase transformation in supersaturated $\mathrm{Cu}(\mathrm{Ge})$ solid solutions and similar systems exhibiting characteristics of a martensitic transformation and a 
diffusional transformation. To this end in particular, both in situ and ex situ X-ray diffraction (XRD) studies on $\mathrm{Cu}-\mathrm{Ge}$ powders (with 10.8 at. pct $\mathrm{Ge}$ ) were performed at three isothermal temperatures to quantitatively trace the fcc $\rightarrow$ hcp transformation. The kinetics of the phase transformation was modeled with the versatile modular model. ${ }^{[14-16]}$ Additional microstructural analysis was performed by optical microscopy and TEM in order to characterize the transformation mechanism and to define the model parameters of the kinetics model.

\section{EXPERIMENTAL PROCEDURES}

\section{A. Specimen Preparation}

$\mathrm{Cu}-\mathrm{Ge}$ alloys with nominal composition of 10.8 at. pct Ge (see the phase diagram in Figure 1) were prepared in molten state in an induction furnace in vacuum at $\sim 1223 \mathrm{~K}\left(950{ }^{\circ} \mathrm{C}\right)$ from pure $\mathrm{Cu}$ and pure $\mathrm{Ge}$ (both 99.999 pet purity by weight) (purchased from Goodfellow GmbH, Germany) and cast into a graphite mold of dimensions $70 \times 50 \times 4.3 \mathrm{~mm}^{3}$. The solid billet was then homogenized at $1023 \mathrm{~K}\left(750^{\circ} \mathrm{C}\right)$ for 24 hours in a quartz tube under $\mathrm{Ar}$ atmosphere and quenched into ice-water. The chemical composition of the homogenized billet was confirmed, by inductively coupled plasma optical emission spectrometry (ICP-OES), to be identical to the nominal composition, i.e., 10.8 at. pct Ge.

Powder material (particle size $\leq 25 \mu \mathrm{m}$ ) was produced by filing and sieving through a $25 \mu \mathrm{m}$ sieve. The sieved powder was encapsulated in a quartz tube under $\mathrm{Ar}$ atmosphere and it was annealed at $1023 \mathrm{~K}\left(750^{\circ} \mathrm{C}\right)$ for 24 hours followed by ice-water quenching to completely remove the deformation induced by the

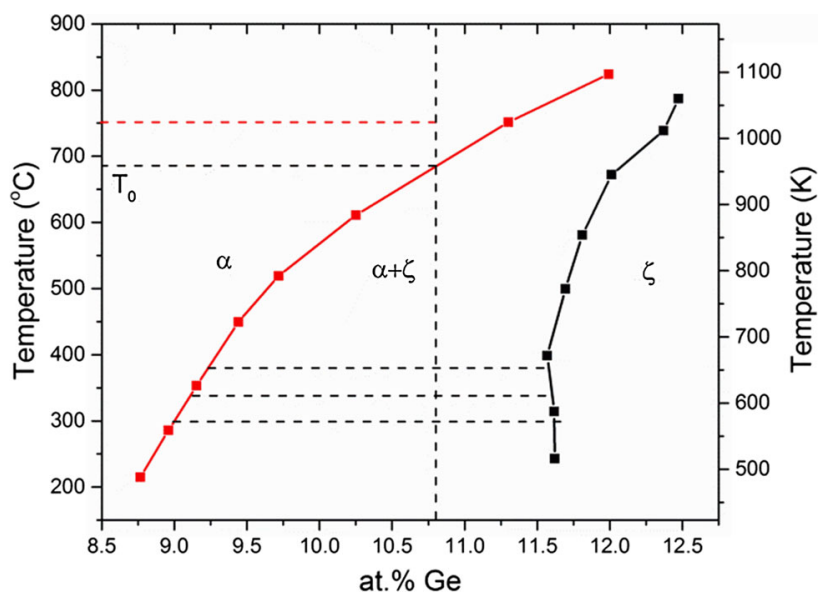

Fig. 1-Magnified region of the $\mathrm{Cu}-\mathrm{Ge}$ phase diagram showing the nominal composition of the material of the present work (i.e., 10.8 at. pct $\mathrm{Ge}$ ) and the isothermal temperatures applied to the quenched, supersaturated $\alpha-\mathrm{Cu}(\mathrm{Ge})$ solid solutions in order to develop the $\zeta$-phase. Solution annealing at $1023 \mathrm{~K}\left(750{ }^{\circ} \mathrm{C}\right)$ and ice-water quenching was used to produce supersaturated $\alpha-\mathrm{Cu}(\mathrm{Ge})$ solid solution specimens that under thermodynamic equilibrium are composed of $\zeta$-phase and $\alpha-\mathrm{Cu}(\mathrm{Ge})$ (shown by the red dashed line), reproduced using data from Ref. [8] (Color figure online). powder-preparation procedure and to avoid formation of the $\zeta$-phase. Thus the powder consisted of (loosely sintered) particles of supersaturated $\mathrm{Cu}(\mathrm{Ge})$ solid solution. The powder particles were composed of grains with mean size of approximately $15 \mu \mathrm{m}$, as determined by optical microscopy. Pieces of the (loosely) sintered material were cut and mounted on the specimen holder of the diffractometer and subjected to annealing and in situ XRD investigation ( $c f$. Section II-B).

Additional $\mathrm{Cu}-\mathrm{Ge}$ specimens in sheet form were produced by cold-rolling as-cast and homogenized ingots 3 times (each round of cold-rolling consisted of $\sim 50$ pct reduction in thickness) with intermediate annealings at $853 \mathrm{~K}\left(580^{\circ} \mathrm{C}\right)$ for 2 hours. The final heat treatment was conducted at $1023 \mathrm{~K}\left(750{ }^{\circ} \mathrm{C}\right)$ for only 5 minutes, in order to dissolve the $\zeta$-phase that was formed by the deformation induced by rolling, but simultaneously to avoid significant grain growth (the grain size was $\sim 50 \mu \mathrm{m}$, as measured by optical microscopy). The relatively large grain size is inappropriate for most XRD studies (due to unsatisfactory crystal statistics) but does not obstruct microscopy investigations. Specimens for microscopy were prepared from the sheet material, by encapsulating small pieces in quartz tubes under Ar atmosphere. The microstructure was investigated by optical microscopy and TEM for several annealing times at $613 \mathrm{~K}\left(340{ }^{\circ} \mathrm{C}\right)$.

Pieces of the isothermally aged sheet specimens were ground with 1000,2500 , and $4000 \mathrm{SiC}$ papers and polished with 3,1 , and $0.25 \mu \mathrm{m}$ diamond suspension.

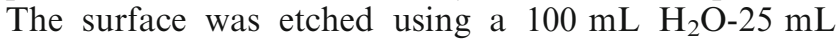
HCl-5 $\mathrm{g} \mathrm{FeCl}_{3}$ solution for 3 to 4 seconds to reveal the grain boundaries and subjected to optical microscopy analysis ( $c f$. Section II-C).

Specimens for TEM analysis were prepared by cutting a disk with wire erosion from a sheet specimen that was annealed at $613 \mathrm{~K}\left(340{ }^{\circ} \mathrm{C}\right)$ for $\sim 8$ days to produce a significant amount of $\zeta$-phase. The planar surfaces of the disks were mechanically ground so that the thickness was reduced to $100 \mu \mathrm{m}$. The disks were further thinned to $20 \mu \mathrm{m}$ using a dimple grinder (Gatan model 656, Gatan $\mathrm{GmbH}$, München, Germany) followed by ion milling (using a PIPS ${ }^{\mathrm{TM}}$ Gatan model 691 operated at $\sim 2.7 \mathrm{keV}$, with a beam-angle of $\sim 7 \mathrm{deg}$, applying liquid nitrogen specimen cooling to avoid artifacts) such that electron-transparent specimens were obtained ( $c f$. Section II-C).

\section{B. In Situ and Ex Situ XRD; Isothermal Annealing Experiments}

The sintered powder specimens were mounted on a MRI-TCPU1 heating unit (covered by a Be dome), which was placed onto a Bruker TSX diffractometer, operating in Bragg-Brentano geometry, using $\mathrm{CuK}_{\alpha}$ radiation (at $50 \mathrm{kV}, 20 \mathrm{~mA}$ ), a $0.5-\mathrm{mm}$ pinhole collimator and a Vantec-500 2D detector. The measurements were conducted in vacuum $\left(\sim 5 \times 10^{-4}\right.$ bar $)$ at $573 \mathrm{~K}$, $613 \mathrm{~K}$, and $653 \mathrm{~K}\left(300{ }^{\circ} \mathrm{C}, 340{ }^{\circ} \mathrm{C}\right.$, and $\left.380{ }^{\circ} \mathrm{C}\right)$. The $2 \mathrm{D}$ diffraction frames obtained (with counting time of 60 seconds per frame and 300 seconds waiting time) comprised the $2 \theta$ range of 28 to $56 \mathrm{deg}$ and they were 
integrated at constant $2 \theta$ along the Euler $\psi$-angle range from -111 to $-69 \mathrm{deg}$. The maximum exposure time for the in situ experiments, at each isothermal temperature, was approximately 24 hours.

The total exposure times reached with the in situ experiments, for each powder specimen, were further extended by incremental isothermal annealings in a chamber furnace followed by ex situ XRD measurements reaching a total annealing time of $\sim 4$ weeks for every specimen. To this end the powder specimens were encapsulated, after the in situ experiments, in quartz tubes under Ar atmosphere and were isothermally aged, at $573 \mathrm{~K}, 613 \mathrm{~K}$, and $653 \mathrm{~K}\left(300{ }^{\circ} \mathrm{C}, 340{ }^{\circ} \mathrm{C}\right.$, and $\left.380{ }^{\circ} \mathrm{C}\right)$. The ex situ XRD measurements were performed on an X'pert PANalytical diffractometer, in theta-theta geometry, employing $\mathrm{CoK}_{\alpha}$ radiation (at 40 $\mathrm{kV}, 40 \mathrm{~mA}$ ) and a PANalytical X'Celerator linear position-sensitive detector (1D silicon strip detector), covering a range of $2.122 \mathrm{deg} 2 \theta$ per measurement step, along a range of $25 \mathrm{deg}$ in $2 \theta$ with $0.033 \mathrm{deg} 2 \theta$ step-size and 6.4 seconds counting time per step.

For investigating the evolution of $\zeta$-phase in the bulk material with time, pieces of the sheet specimens were isothermally annealed at $613 \mathrm{~K}\left(340{ }^{\circ} \mathrm{C}\right)$ for different times. XRD investigation was performed ex situ employing a high-resolution Philips X'pert diffractometer using $\mathrm{CuK}_{\alpha 1}$ radiation (at $40 \mathrm{kV}, 40 \mathrm{~mA}$ ) selected by a curved Ge monochromator in the incident beam and a PANalytical X'Celerator linear position-sensitive detector (1D silicon strip detector), covering a range of 2.214 deg $2 \theta$ per measurement step, along a range of $15 \mathrm{deg}$ in $2 \theta$ with $0.017 \mathrm{deg} 2 \theta$ step-size and 9 seconds counting time per step. The illuminated area of the sample was restricted by a $5 \times 13 \mathrm{~mm}^{2}$ mask, thus effectively averaging over a large area while the sample holder was spinning to improve the experimental accuracy due to the relatively large grain size of the bulk material (grain size of $\sim 50 \mu \mathrm{m}$; see above).

The diffraction profiles obtained from both the in situ and ex situ experiments with both powder and sheet specimens were fitted utilizing the PANalytical HighScore software. The phase fraction of the $\zeta$-phase was calculated using integrated intensities of the $100_{\zeta}$ and $200_{\alpha}$ reflections of the $\alpha-\mathrm{Cu}(\mathrm{Ge})$ phase according to Reference 17:

$$
f_{\zeta}=\frac{I_{\zeta(100)}}{I_{\alpha(200)}+I_{\zeta(100)}},
$$

where $I_{(\mathrm{hkl})}$ is the integrated intensity of the corresponding reflection. The error bars shown (in Figure 7) represent the counting statistical inaccuracy of the XRD measurements.

\section{Microscopy Studies}

Optical microscopy images were taken from the specimens with a Zeiss Axiophot microscope equipped with a ColorView IIIu CCD camera.

TEM investigations were performed using a Philips CM200 microscope operated at $200 \mathrm{keV}$. A Gatan CCD camera, attached to the microscope, was used to capture bright-field (BF) and dark-field (DF) images and selected area diffraction patterns (SADPs). The local compositional analysis was performed by utilizing an energy-dispersive X-ray detection system (EDX) on the Philips CM200 TEM instrument. Data analysis was performed using the software Gemini from EDAX. The values for the $\mathrm{Cu}$ and $\mathrm{Ge}$ content were determined from the measured characteristic X-ray intensities using a correction factor $K_{\mathrm{CuGe}}$ derived from a standard material, as follows:

For a material composed of two elements, $i$ and $j$, the unknown composition of a specimen can be obtained, by application of the following relation ${ }^{[18]}$ :

$$
\frac{C_{i}}{C_{j}}=\frac{I_{i}}{I_{j}} K_{i j},
$$

where $C_{i}, C_{j}, I_{i}$, and $I_{j}$ are the compositions and the characteristic X-ray intensities of the elements $i$ and $j$, respectively. The instrument-dependent correction factor $K_{i j}$ can be derived from a standard specimen of known composition. To this end a solid solution of $\mathrm{Cu}$ with 8 at. pet Ge (as confirmed by ICP-OES) was used. The standard specimen was cast and TEM specimens were prepared similarly as described in Section II-A. Several EDX measurements were undertaken on the reference material. With the known concentrations of the standard material, $C_{\mathrm{Cu}}$ and $C_{\mathrm{Ge}}$, and the measured values of the corresponding characteristic X-ray intensities, $I_{\mathrm{Cu}}$ and $I_{\mathrm{Ge}}$, the microscope-dependent correction factor $K_{\mathrm{CuGe}}=1.29$ was determined using Eq. [2].

Then, applying Eq. [2] again by using the constant $K_{\mathrm{CuGe}}$ and the measured values of the characteristic X-ray intensities $I_{\mathrm{Cu}}$ and $I_{\mathrm{Ge}}$ pertaining to the actual specimen, a value for the local composition of the specimen was obtained.

\section{MODEL FOR TRANSFORMATION KINET- ICS DESCRIPTION}

\section{A. The fcc $\rightarrow$ hep Transformation}

A (perfect) dislocation in an fcc crystal may dissociate on a closed-packed plane into two partial dislocations separated by a stacking fault (SF) because this lowers the total energy. ${ }^{[19]}$ It has been reported that SFs (intrinsic in nature) are the principal lattice defects observed in supersaturated $\mathrm{Cu}(\mathrm{Ge})$ solid solutions when quenched from solution temperatures, down to room temperature. ${ }^{[1,9]}$

The allotropic fcc $\rightarrow$ hcp phase transformation (e.g., in the Co-Ni system) takes place by a change in the stacking sequence of the closed-packed planes (from fcc to hcp): the glide in a common direction for a stack of closed-packed layers of Shockley partial dislocations, with a $1 / 6 a\langle 112\rangle_{\mathrm{fcc}}=1 / 3 a\langle 1 \overline{1} 00\rangle_{\mathrm{hcp}}$-type Burgers vector, ${ }^{[20]}$ along every alternate (every second) closed-packed plane, ${ }^{[21]}$ changes the stacking sequence of the closed-packed planes in the stack considered from fcc (ABCABC...) to hcp (ABABAB...), or vice versa. 


\section{B. The Transformation Kinetics}

The modular model ${ }^{[15,16,22,23]}$ is a versatile, flexible tool for the description of transformation kinetics that has been applied successfully to a wide range of diverse transformations. ${ }^{[24]}$ The model consists of three modules that separately specify modes of nucleation, growth, and impingement of the growing product phase. This model, as used particularly for characterizing the kinetics of $\zeta$-phase formation in the supersaturated $\alpha-\mathrm{Cu}(\mathrm{Ge})$ solid solution, is described below.

\section{Nucleation mode}

The fcc $\rightarrow$ hcp transformation is established by "ordered glide" of an array of Shockley partial dislocations (SPs), originating from the dissociation of a perfect dislocation, on every second closed-packed plane (where it is assured that microscopic shear cancels out over short distances ${ }^{[7,25]}$ ). The region between the two separated arrays of SPs can be conceived as two product (hcp) phase particles (References 7 and 20 see Figure 2).

The (arrays of) dislocations are present from the beginning with a height distribution. It can be shown that a certain critical size (half of the separation distance of the SPs of a pair gliding in opposite directions) does not occur: the nucleation is athermal (i.e., "spontaneous nucleation"). ${ }^{[7,20]}$ The larger the height of the dislocation array, the smaller the undercooling required to "activate" the corresponding array of dislocations, implying that the minimum, critical height decreases with temperature. Hence, the nucleation during cooling can be conceived as "site saturation" at each temperature, where arrays of specific height start to operate.
It has been suggested (for martensitic transformations ${ }^{[20,26,27]}$ ) to describe the cumulative (during cooling) number of operating dislocation arrays, $N^{*}$, by

$$
N^{*}\left(n^{*}(\Delta T(t))=N_{\text {tot }} \exp \left(-n^{*}(\Delta T(t))\right)\right.
$$

where $n^{*}$ is a dimensionless minimum (critical) height of the dislocation array (given in number of closed-packed layers) which depends on temperature; $N_{\text {tot }}$ is the total number of pre-existing Shockley partial dislocation arrays of variable height (per unit volume); and $\Delta T=T-T_{0}$, where $T$ is the aging temperature and $T_{0}$ is the temperature where the $\alpha-\mathrm{Cu}$ solid solution and the $\zeta$-phase are in equilibrium, at a given Ge alloy (overall) concentration, at which the molar fraction of the $\zeta$-phase is zero (i.e., infinitely small) (see Figure 1).

Following the line of reasoning as in Reference 7 it can be derived:

$$
n^{*}(\Delta T(t))=-\frac{2 \sigma}{\frac{c}{2 V_{\mathrm{m}}}\left(\Delta G_{\mathrm{m}}^{\mathrm{ch}}\right)},
$$

where $\sigma$ is the product particle/matrix interface energy (per unit area); $c$ is the distance between adjacent dislocations in the array parallel to the c-axis (see Figure 2); $V_{\mathrm{m}}$ is the molar volume; and $\Delta G_{\mathrm{m}}^{\text {ch }}$ is the difference in chemical Gibbs energy (per mole) of product and parent phases. For the present case, the change in (specific) volume upon phase transformation is very small, i.e., -0.07 pct (calculated from the lattice-parameter data provided in Reference 28, $c f$. Table I). Hence, the contribution of elastic strain energy can be neglected in the present treatment.

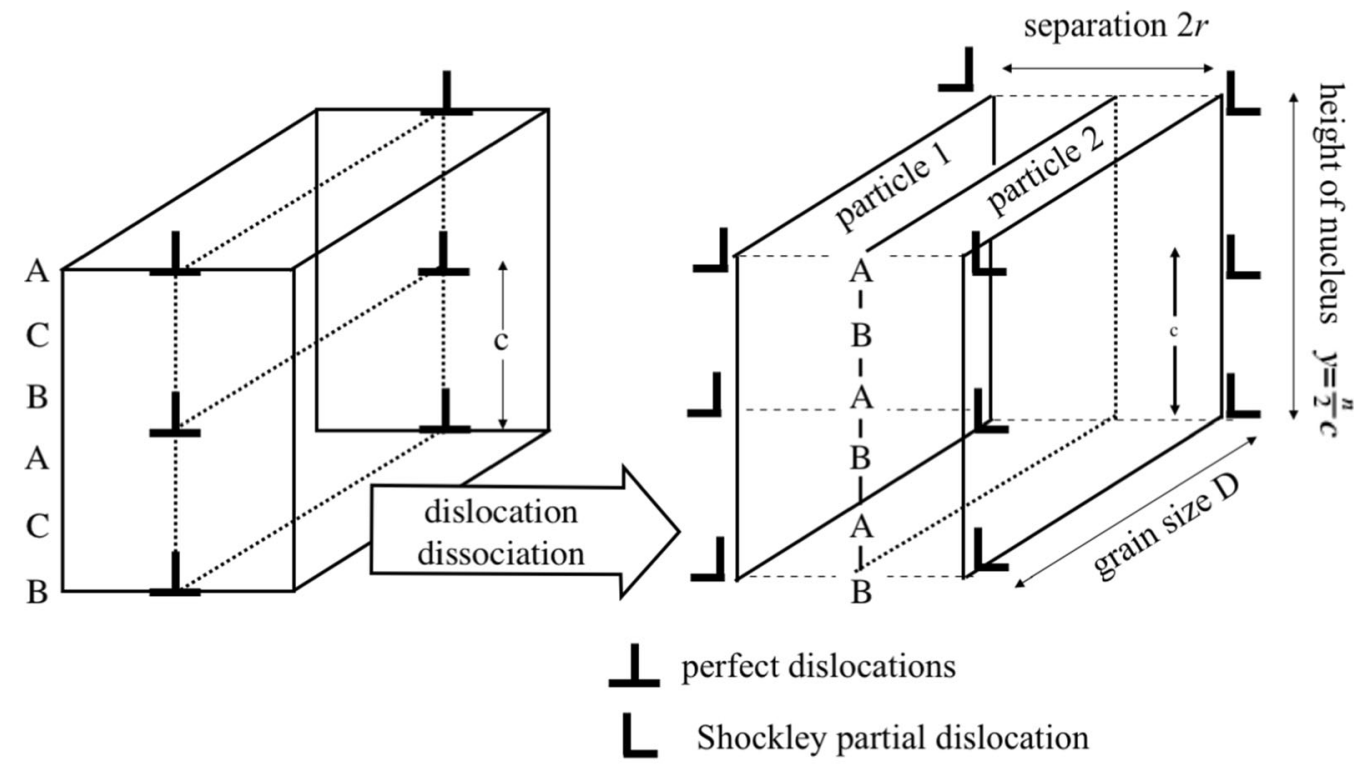

(a)

(b)

Fig. 2-(a) Schematic of an hcp nucleus (with stacking sequence ABAB...) developing in an fcc matrix with stacking sequence (ABCABC...) by dissociation of three perfect dislocations into two arrays of three Shockley partial dislocations thereby forming two particles of hep phase. The volume and interfacial surface of the particle can be calculated from the dimensions of the particle as given in (b) adapted from Ref. [7], Taylor \& Francis Ltd www.tandfonline.com. 
Table I. Lattice-Parameter and Unit Cell Data for the $\alpha$-Cu(Ge) Solid Solution (Containing 10.8 At. Pct Ge; fcc) and the $\zeta$-Phase (hep)

\begin{tabular}{|c|c|c|}
\hline Crystal Structure & Lattice Parameter $(\mathrm{nm})^{[28]}$ & Unit Cell Volume $\left(V_{\text {cell }}\right.$, in $\left.\mathrm{nm}^{3} \mathrm{~mol}^{-1}\right)$ \\
\hline $\begin{array}{l}\alpha, \text { fcc } \\
\zeta, \text { hep }\end{array}$ & $\begin{array}{l}a=0.3651 \\
a=0.2578 \\
c=0.4225\end{array}$ & $\begin{array}{l}a^{3}=0.04867 \\
3 a^{2} c=0.07295\end{array}$ \\
\hline
\end{tabular}

Table II. Values of Parameters Used in the Nucleation Model and in the Growth Models (Interface-Controlled and Diffusion-Controlled Growth Modes)

\begin{tabular}{|c|c|c|}
\hline Parameter & Value & Method/Source \\
\hline \multicolumn{3}{|l|}{ Nucleation model } \\
\hline Number of pre-existing nuclei, $N_{\text {tot }}$ & $2.1 \times 10^{19} \mathrm{~m}^{-3}$ & present work (calculated) \\
\hline Grain size, $D$ & $15 \times 10^{-6} \mathrm{~m}$ & present work (optical microscopy) \\
\hline Lattice parameter, $c$ at room temperature & $0.4225 \times 10^{-9} \mathrm{~m}$ & Ref. [28] \\
\hline Chemical driving force, & $-23.58 \mathrm{~kJ} \mathrm{~mol}^{-1}\left[573 \mathrm{~K}\left(300^{\circ} \mathrm{C}\right)\right]$ & Ref. [29] \\
\hline$\Delta G_{\mathrm{m}}^{\mathrm{ch}} \equiv G_{\mathrm{m}, \zeta}^{\mathrm{ch}}-G_{\mathrm{m}, a-\mathrm{Cu}(\mathrm{Ge})}^{\mathrm{ch}}$ & $\begin{array}{l}-18.49 \mathrm{~kJ} \mathrm{~mol}^{-1}\left[613 \mathrm{~K}^{-1}\left(340{ }^{\circ} \mathrm{C}\right)\right] \\
-12.60 \mathrm{~kJ} \mathrm{~mol}^{-1}\left[653 \mathrm{~K}\left(380^{\circ} \mathrm{C}\right)\right]\end{array}$ & SGTE database Version 5.0 \\
\hline \multicolumn{3}{|l|}{ Interface-controlled growth } \\
\hline Interface velocity, $v_{0}$ & $4000 \mathrm{~m} \mathrm{~s}^{-1}$ & $\begin{array}{l}\text { present work (calculated with } \\
\text { data from Ref. [32]) }\end{array}$ \\
\hline Interface energy, $\sigma$ & $0.0058 \pm 0.0052 \mathrm{~mJ} \mathrm{~m}^{-2}$ & extrapolated from Ref. [30] \\
\hline \multicolumn{3}{|l|}{ Diffusion-controlled growth } \\
\hline Pre-exponential factor for diffusion, $D_{0}$ & $3.15 \times 10^{-5} \mathrm{~m}^{2} \mathrm{~s}^{-1}$ & Ref. [34] \\
\hline Interface energy, $\sigma$ & $0.0058 \pm 0.0052 \mathrm{~mJ} \mathrm{~m}^{-2}$ & extrapolated from Ref. [30] \\
\hline
\end{tabular}

Using the Thermo-Calc software ${ }^{[29]}$ and the SGTE database for Solid Solutions Version 5.0, the chemical driving force, $\Delta G_{\mathrm{m}}^{\mathrm{ch}}$, for the $\zeta$-phase formation from $\alpha-\mathrm{Cu}(\mathrm{Ge})$ containing 10.8 at. pet $\mathrm{Ge}$ was calculated to be $-23.58,-18.49$, and $-12.60 \mathrm{~kJ} \mathrm{~mol}^{-1}$ at $573 \mathrm{~K}$, $613 \mathrm{~K}$, and $653 \mathrm{~K}\left(300{ }^{\circ} \mathrm{C}, 340{ }^{\circ} \mathrm{C}\right.$, and $\left.380{ }^{\circ} \mathrm{C}\right)$, respectively. As a consequence, the number of operating dislocation arrays, $N^{*}$ (cf. Eq. [3]) decreases with increasing temperature.

The total number of pre-existing SP arrays, $N_{\text {tot }}$, can be approximated by ${ }^{[7]}$

$$
N_{\mathrm{tot}} \approx \frac{2}{c D^{2}}
$$

where $D$ is the size of the product particle (defined as the grain size of parent phase) and the number two originates from the recognition that every perfect dislocation, upon dissociation, contributes to the formation of two particles (see Figure 2). For the present material, it thus follows approximately $N_{\text {tot }}=2.1 \times 10^{19} \mathrm{~m}^{-3}$.

The interfacial energy (of the fcc/hcp interfaces), $\sigma$, can be conceived as equal to the stacking fault energy (SFE). ${ }^{[7,25]}$ In the present work, a value of $\sigma$ for $\alpha-\mathrm{Cu}(\mathrm{Ge})$ with 10.8 at. pet Ge was obtained by adopting the procedure given in Reference 30 that related the SFE to the solute concentration in a $\mathrm{Cu}(\mathrm{Ge})$ solid solution: $\sigma=0.0058 \pm 0.0052 \mathrm{~mJ} \mathrm{~m}^{-2}$ (taken as constant for the annealing temperature range in the present work). Note that the SFE does not change significantly with temperature in the range of $300 \mathrm{~K}$ to $600 \mathrm{~K}\left(27^{\circ} \mathrm{C}\right.$ to $\left.327^{\circ} \mathrm{C}\right)$ in the $\mathrm{Cu}-\mathrm{Ge}$ and $\mathrm{Cu}-\mathrm{Si}$ systems ${ }^{[30,31]}$ ).

The measured/calculated parameters and the fit parameters, for the nucleation mechanism, have been summarized in Table II. Note that the temperature dependence of $c$ has been neglected as it does not affect the value of $N_{\text {tot }}$ significantly.

\section{Growth mode}

The fcc $(\alpha) \rightarrow$ hcp $(\zeta)$ phase transformation in the $\mathrm{Cu}-\mathrm{Ge}$ system generally involves compositional change, in combination with the structural change. The (distinctly) slowest of these mechanisms controls the kinetics of the fcc $\rightarrow$ hcp phase transformation in supersaturated $\mathrm{Cu}(\mathrm{Ge})$ solid solutions. The growth can therefore be controlled by either diffusion (of $\mathrm{Ge}$ in $\mathrm{Cu}$ ) and/or by the motion of the product/parent interface (i.e., the glide of SPs, $c f$. Section III-B-1). In the present study, both growth mechanisms have been considered and fitted to the experimental data; the quality of the fit obtained can be used as a criterion to decide which growth mechanism can be dominating.

Both growth modes can be formulated in a compact way by the same equation. ${ }^{[15,16,22,23]}$ At time $t$, the volume $Y$ of a growing particle nucleated at time $\tau$ can be given by

$$
Y(t, \tau)=g\left(\int_{\tau}^{t} v \mathrm{~d} t\right)^{d / m}
$$

where $g$ is a particle-geometry factor (here $g=D n^{*} c / 2$, see schematic of a growing $\zeta$-phase plate in Figure 2, where $n^{*} c / 2$ is the minimum (critical) height/size of the nucleus; $n^{*} / 2$ is the number of dislocations within the array of dislocations oriented perpendicular to the stacking direction ( $n^{*}$ is the number of closed-packed layers in the stack considered and $c$ is the distance 
between adjacent dislocations in the array parallel to the $c$ axis) $){ }^{[7,25]}$

The dimensionality of the growth is expressed by the parameter $d(d=1,2,3)$. In the present case, the product particle can only grow (lengthen) in one of the three possible $\langle 0 \overline{1} 10\rangle$ directions oriented perpendicular to the c-axis and therefore $d=1$ (it is assumed that the thickening is negligible, see below). The growth mode parameter, $m$, can take one of the two values: $m=1$ for interface-controlled growth or $m=2$ for volume diffusion control growth. Finally, $v$ is the growth velocity (velocity of the product/parent interface) in case of interface-controlled growth or $v$ is the diffusion coefficient in case of diffusion-controlled growth. ${ }^{[14,23]}$ The height of the particle $\left(=n^{*} c / 2\right.$, see Figure 2$)$ is assumed to remain constant as a function of time, i.e., zero "thickening" as "thickening" of the plates is considered negligible compared to the "lengthening" of the plates, at the isothermal temperatures used in the present work (see the footnote*).

*Fitting the kinetics model to the experimental data upon incorporation of a "thickening" growth mode (additional to the "lengthening" growth mode) by dislocation climb did not alter the results significantly; dislocation climb is very much slower than dislocation glide.

For the case of interface-controlled growth, the interface velocity, $v$ (for low thermodynamic driving force, i.e., $\left.\Delta G_{\mathrm{m}}^{\mathrm{ch}}<R T\right)$ is given by ${ }^{[14,23]}$

$$
v=M_{0} \exp \left(-\frac{Q_{\mathrm{G}}}{R T}\right)\left(-\Delta G_{\mathrm{m}}^{\mathrm{ch}}\right),
$$

where $Q_{\mathrm{G}}$ is the activation energy for growth (taken as a fit parameter in the present study) and $M_{0}$ is the interface mobility, $M_{0}=v_{0} / R T ; v_{0}$ is called the temperature-independent interface velocity. The temperature-independent velocity $v_{0}$ for dislocation glide in $\mathrm{Cu}$ can be calculated from: $\rho_{\mathrm{m}} v_{0}|b|=10^{6} \mathrm{~s}^{-1},{ }^{[32,33]}$ where $\rho_{\mathrm{m}}$ is the density of mobile dislocations and $|b|$ is the size of the Burgers vector for the matrix (for $\alpha-\mathrm{Cu}$ $|b| \approx 2.54 \AA$ ). The density of mobile dislocations, $\rho_{\mathrm{m}}$, was calculated from Reference 32 to be $10^{12} \mathrm{~m}^{-2}$, which holds as a good estimate for annealed fcc metals. ${ }^{[32]}$ It follows that $v_{0}$ is equal to $\sim 4000 \mathrm{~m} \mathrm{~s}^{-1}$. For the case of diffusion-controlled growth, the diffusion coefficient, $v$, is given by ${ }^{[14,23]}$

$$
v=D_{0} \exp \left(-\frac{Q_{\mathrm{D}}}{R T}\right),
$$

where $D_{0}$ is the pre-exponential factor for diffusion (here $D_{0}=3.15 \times 10^{-5} \mathrm{~m}^{2} \mathrm{~s}^{-1}$ as determined for the effective diffusion coefficient of a polycrystalline $\mathrm{Cu} / \mathrm{Ge}$ diffusion couple in Reference 34; a similar, experimentally determined for $\mathrm{Cu}$ single crystals, value for $D_{0}$ has been reported in Reference 35, i.e., $3.97 \times 10^{-5} \mathrm{~m}^{2} \mathrm{~s}^{-1}$ ); $Q_{\mathrm{D}}$ is the activation energy for diffusion of $\mathrm{Ge}$ in $\mathrm{Cu}$ (taken as a fit parameter in the present work). The calculated parameters and the fit parameters, for the growth mechanisms, have been summarized in Table II.
3. The extended volume fraction, $x_{e}$

Combining the nucleation and growth modes described above, the overall extended transformed volume fraction is

$$
x_{\mathrm{e}}=\int_{0}^{t} N^{*} \delta(\tau-0) g\left(\int_{\tau}^{t} v \mathrm{~d} t\right)^{1 / m} \mathrm{~d} \tau,
$$

where $\delta(\tau-0)$ is a Dirac function. Equation [9] upon integration and combination with Eqs. [4, 7] and Eqs. [4, 8], respectively, yields for interface-controlled growth (i.e., $m=1)^{[23]}$.

$$
x_{\mathrm{e}}=N^{*} g\left(\frac{v_{0}}{R T}\right) \exp \left(-\frac{Q_{\mathrm{G}}}{R T}\right) t\left(-\Delta G_{\mathrm{m}}^{\mathrm{ch}}\right)
$$

and for diffusion-controlled growth (i.e., $m=2$ ):

$$
x_{\mathrm{e}}=N^{*} g D_{0}^{1 / 2} \exp \left(-\frac{\frac{1}{2} Q_{\mathrm{D}}}{R T}\right) t^{\frac{1}{2}} .
$$

\section{Impingement Mode}

The real fraction of the product phase can be calculated by applying an impingement mechanism to the overall extended fraction $x_{\mathrm{e}}{ }^{[15]}$ The $\zeta$-phase appears as plates, i.e., the particles are not equiaxed and according to Reference 36 the fast moving interfaces can impinge on slow moving interfaces ("lengthening" of the plates is significantly faster than "thickening"). This impingement mechanism is illustrated schematically in Figure 3(a) and supported by the microstructural evidence presented in Figure 3(b): the arrows indicate characteristic blocking events and impingement at (parent) grain boundaries.** The real fraction, $f$, of

\footnotetext{
**Intersecting bundles of stacking faults have been reported for the as-prepared state in Ref. [9], and are interpreted as consequence of the strains due to the rapid cooling (quenching).
}

the product phase is a function of the extended fraction, $x_{\mathrm{e}}$. The relation between $f$ and $x_{\mathrm{e}}$ due to anisotropic growth ( $c f$. the microstructural characterization) is expressed phenomenologically by Eq. [11], where $\xi$ is the impingement factor. If $\xi=1$, Eq. [11] leads to the Johnson-Mehl-Avrami-Kolmogorov (JMAK equation), if $\xi=2$ to the Austin-Rickett equation. ${ }^{[36,37]}$ The relation used between $f$ and $x_{\mathrm{e}}$ is ${ }^{[16,38,39]}$

$$
\frac{\mathrm{d} f}{\mathrm{~d} x_{\mathrm{e}}}=(1-f)^{\xi}
$$

with $f=f_{\mathrm{XRD}} / f_{\mathrm{s}}$, where $f_{\mathrm{XRD}}$ is the experimentally determined transformed fraction; $f_{\mathrm{s}}$ is the saturation level of the transformation (as determined from the phase diagram, see below); and $\xi$ is the impingement parameter, which can be taken as temperature dependent. $^{[36,39]}$

Upon integration Eq. [11] becomes 


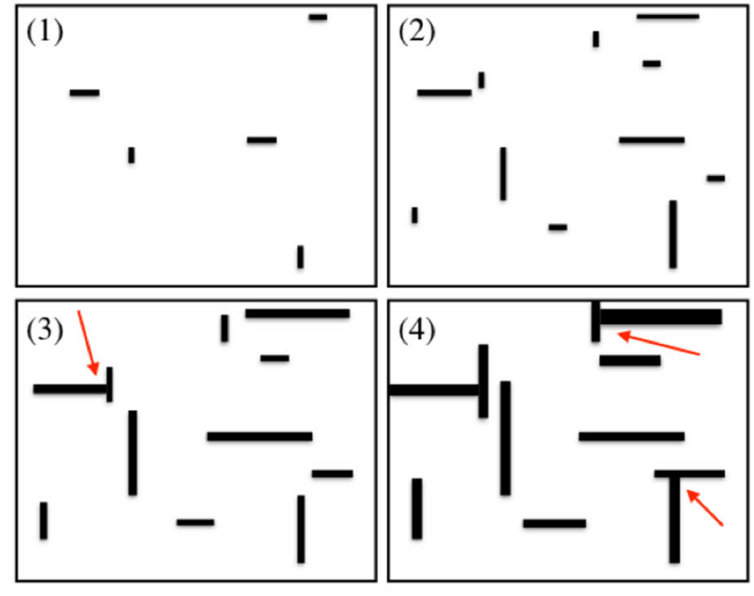

(a)

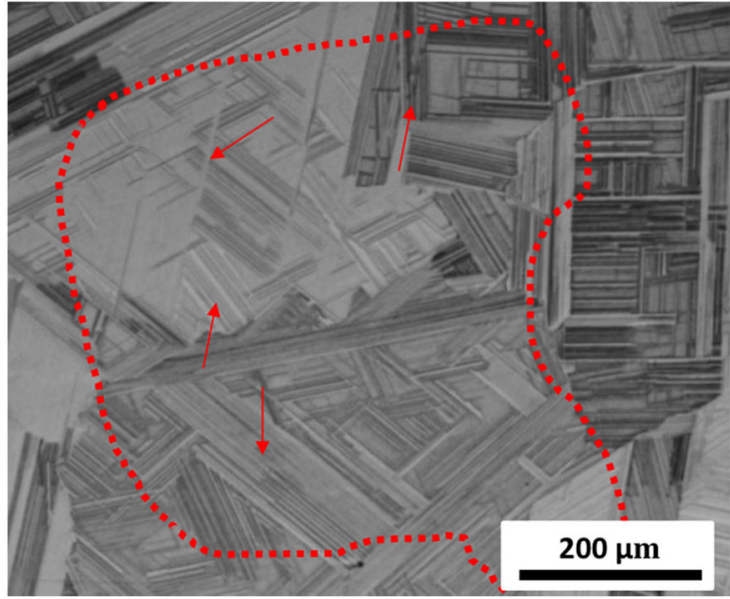

(b)

Fig. 3-(a) Schematic illustration of blocking during the growth (picture $1 \rightarrow$ picture 4) of anisotropic particles. The figure depicts a 2D transformation with nucleation and growth, (adapted from Ref. [36]). (b) Optical microscopy image showing bundles of $\zeta$-phase plates "hitting" upon each other within one large parent grain for sheet material aged at $613 \mathrm{~K}\left(340{ }^{\circ} \mathrm{C}\right)$ for $\sim 8$ days; the red arrows indicate examples of plate-growth blockage (Color figure online).

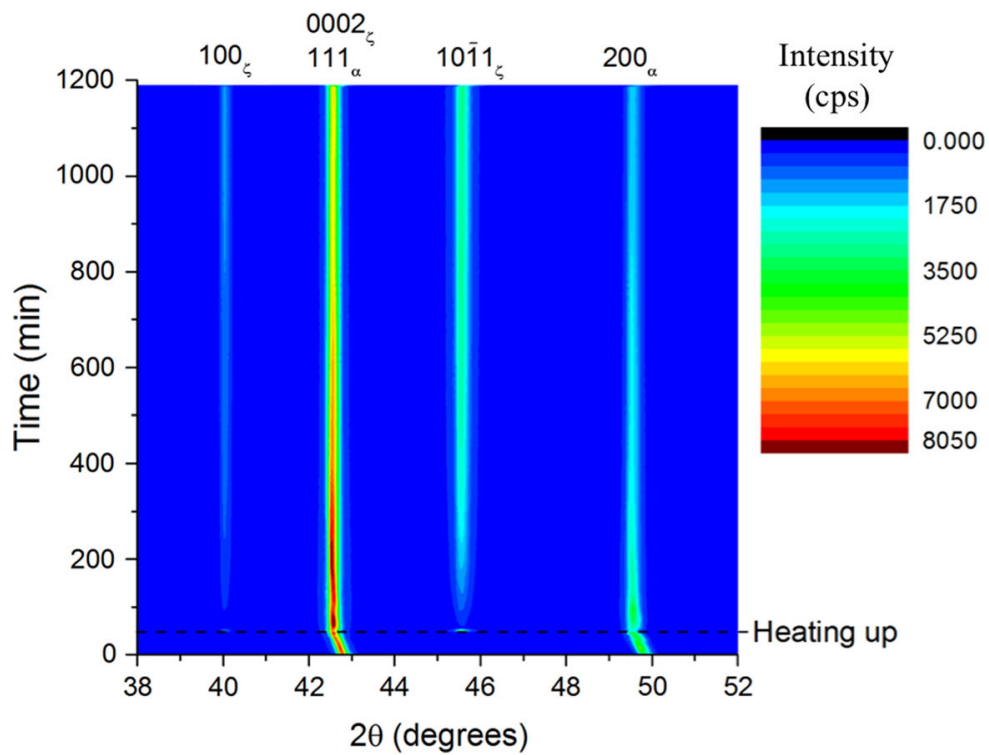

(a)

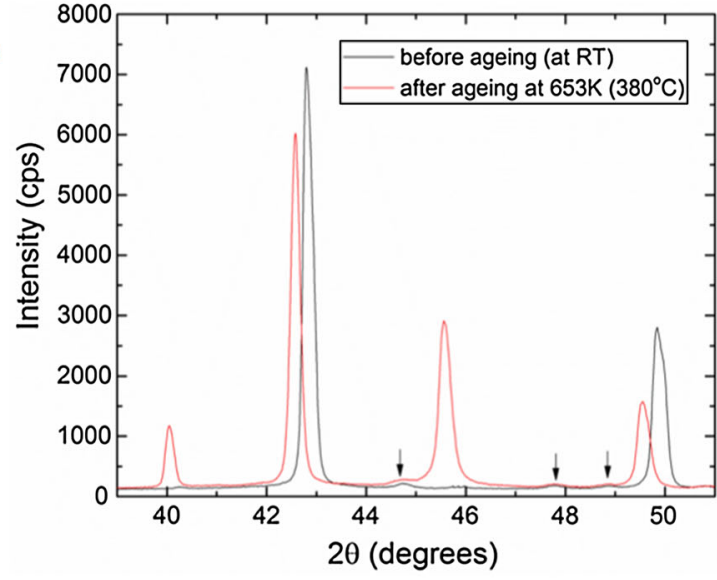

(b)

Fig. 4 - (a) Evolution of the intensity of reflections corresponding to the $\alpha-\mathrm{Cu}(\mathrm{Ge})$ and $\zeta$-phases for powder specimens $\left(\mathrm{CuK} \mathrm{K}_{\alpha}\right.$ radiation; in situ data) with time at $653 \mathrm{~K}\left(380^{\circ} \mathrm{C}\right)$. (b) Diffraction patterns before aging (at $\left.R T\right)$ and after aging at $653 \mathrm{~K}\left(380{ }^{\circ} \mathrm{C}\right)$ for $\sim 70 \times 10^{3} \mathrm{~s}$; the arrows indicate weak reflections originating from the Be dome ( $c f$. Section II-B).

$$
f_{\mathrm{XRD}}=f_{\mathrm{s}}-f_{\mathrm{s}}\left[1+(\xi-1) x_{\mathrm{e}}\right]^{-1 /(\xi-1)} .
$$

Application of the lever rule to the enlarged section of the $\mathrm{Cu}-\mathrm{Ge}$ phase diagram (for 10.8 at. pet $\mathrm{Ge})^{[8]}$ shown in Figure 1 indicates that the $\zeta$-phase fraction saturation level, $f_{\mathrm{s}}$ is approximately the same for all isothermal temperatures employed in this study [i.e., $573 \mathrm{~K}, 613 \mathrm{~K}$, and $653 \mathrm{~K}\left(300{ }^{\circ} \mathrm{C}, 340{ }^{\circ} \mathrm{C}\right.$, and $\left.\left.380{ }^{\circ} \mathrm{C}\right)\right]$ and equals $\sim 0.68$.

\section{RESULTS AND DISCUSSION}

The XRD pattern recorded as a function of annealing time at $653 \mathrm{~K}\left(380{ }^{\circ} \mathrm{C}\right)$ is shown in Figure 4. Initially only reflections of the $\alpha-\mathrm{Cu}(\mathrm{Ge})$ phase are present [Note the initial peak-position shifts of the $\alpha-\mathrm{Cu}(\mathrm{Ge})$ reflections to lower diffraction angles due to the thermal expansion during heating up in the first minutes (until about 2900 seconds)], $\zeta$-phase reflections emerge after approximately $5 \times 10^{3}$ seconds of annealing. The intensity of the $\zeta$-phase reflections increases with time at the 


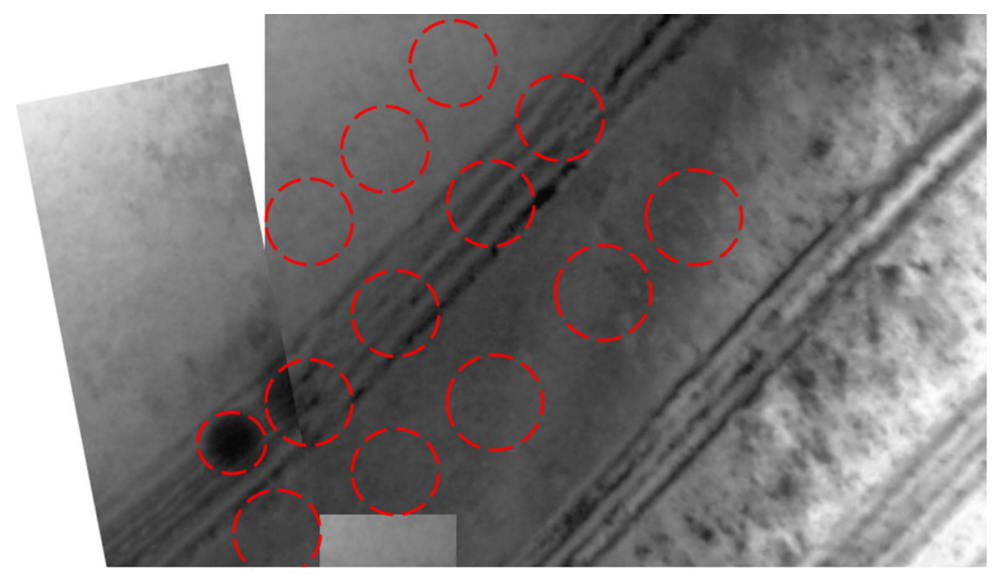

(a)

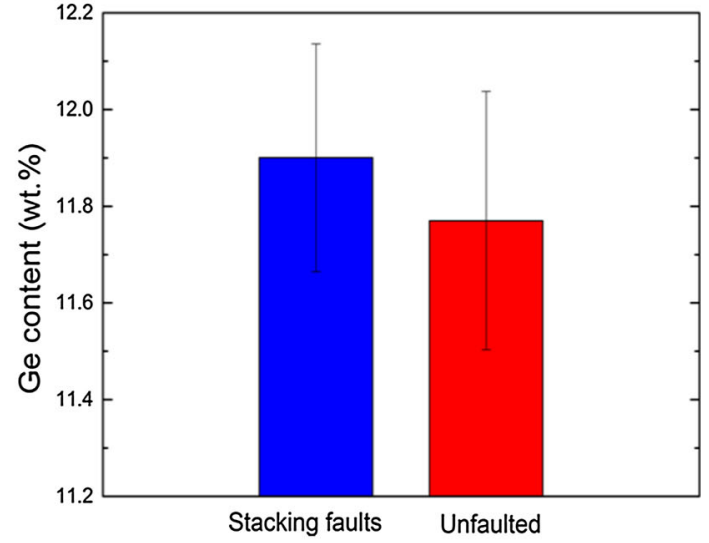

(b)

Fig. 5- (a) Bright-field image of a Cu-Ge sheet specimen aged at $613 \mathrm{~K}\left(340{ }^{\circ} \mathrm{C}\right)$ for 8 days showing a bundle of SFs. (b) Results of the local EDX analyses: Average Ge content (in at. pct) of the regions inside the SF bundle (blue bar) and of the regions without SFs (red bar). The error bars correspond to the standard deviation of the measurements (Color figure online).

expense of the intensity of the $\alpha-\mathrm{Cu}(\mathrm{Ge})$ reflections as a consequence of the occurring fcc $(\alpha) \rightarrow$ hcp $(\zeta)$ transformation. The first occurrence of $\zeta$-phase at $573 \mathrm{~K}$ and $613 \mathrm{~K}\left(300{ }^{\circ} \mathrm{C}\right.$ and $\left.340{ }^{\circ} \mathrm{C}\right)$ was observed after $10 \times 10^{3}$ and $21 \times 10^{3}$ seconds, respectively.

\section{A. Microstructure}

A series of EDX measurements were taken at various locations within and outside a faulted region of $\alpha-\mathrm{Cu}(\mathrm{Ge})$ (also here the absence of $\zeta$-phase was confirmed by the SADP), as shown in Figure 5. It follows that the average Ge content within regions of SFs is higher (within the statistical certainty pertaining to the series of EDX measurements) than that of the surrounding area (cf. Figure 5(b)). This indicates that $\mathrm{Ge}$ enrichment of (at least a fraction of) the SFs (by depletion of the surrounding area) occurs before the $\alpha \rightarrow \zeta$ transformation takes place.

The BF TEM image in Figure 6 shows another faulted $\alpha-\mathrm{Cu}(\mathrm{Ge})$ region of the same specimen [aged at $613 \mathrm{~K}\left(340{ }^{\circ} \mathrm{C}\right)$ for 8 days]. In this case, the presence of $\zeta$-phase is revealed by the SADP taken at this location, i.e., diffraction spots were observed that correspond to $\alpha-\mathrm{Cu}(\mathrm{Ge})$ and additional spots that correspond to the $\zeta$-phase (see Figure 6(d) and the corresponding schematic diffraction pattern shown in Figure 6(e)). The locations of the diffraction spots of the two phases are compatible with the orientation relation$\operatorname{ship}(11 \overline{1}) \alpha / /(0001) \zeta,[\overline{1} 10] \alpha / /[11 \overline{2} 0] \zeta \quad(c f$. Section I). Outside the faulted region only $\alpha-\mathrm{Cu}(\mathrm{Ge})$ phase exists (see SADP in Figure 6(c)). The $\zeta$-phase plates are seen to be long along the [0110] direction of the hcp crystal structure (one of the three possible, equivalent directions), whereas the thickness parallel to the [111] direction of the $\alpha-\mathrm{Cu}(\mathrm{Ge})$ is (very) limited to only a few nanometers. This observation suggests that growth of the $\zeta$-plates is dominated by lengthening, justifying the selection of $d=1$ in the growth model (see Section III-B-2).
The observations reported and discussed in the above two paragraphs indicate that the formation of $\zeta$-phase occurs heterogeneously in the sense that $\zeta$-phase has developed already at some SFs, while at other faulted regions only Ge enrichment has occurred.

Using the $01 \overline{1} 0$ diffraction spot of the $\zeta$-phase (see Figure 6(e)), the microstructure of the $\zeta$-plates is revealed in the corresponding dark-field (DF) image (Figure 6(b)). It follows that the thicker $\zeta$-phase plates actually are constituted of several thin ones.

EDX conducted at the locations shown in Figure 6(a) revealed that the atomic fraction of Ge is 13.1 at. pct inside the faults, i.e., where the $\zeta$-phase resides. This composition of the $\zeta$-phase is compatible with the $\mathrm{Cu}-\mathrm{Ge}$ phase diagram ( $c f$. Figure 1). The surrounding area contains about 10.8 at. pct $\mathrm{Ge}$, which is equal to the nominal composition. Note that in the case of completed formation of $\zeta$-phase, a Cu-rich matrix should contain approximately 9 at. pct $\mathrm{Ge}$ in solid solution, at the isothermal temperatures of this work; $c f$. Figure 1. Previous work on a similar system, i.e., $\mathrm{Cu}(\mathrm{Si})$, has shown that the Si depletion zone, around a faulted region of $\mathrm{Cu}(\mathrm{Si})$, has an extent of approximately 2 to 4 $\mathrm{nm}^{[40]}$ which is much smaller than the spatial resolution of the EDX technique used in the present work (the spot size here was $80 \mathrm{~nm}$ for the EDX analyses pertaining to Figure 6). Therefore, a Ge-depleted zone surrounding the $\zeta$-phase plates in the $\alpha-\mathrm{Cu}(\mathrm{Ge})$ matrix could not be observed.

\section{B. Transformation Kinetics}

The dependence of the amount of $\zeta$-phase fraction on annealing time at $573 \mathrm{~K}, 613 \mathrm{~K}$, and $653 \mathrm{~K}\left(300^{\circ} \mathrm{C}\right.$, $340{ }^{\circ} \mathrm{C}$, and $380{ }^{\circ} \mathrm{C}$ ) is shown in Figure 7 ( $c f$. Section II-B). Results of fitting the kinetic model, presented in Section IV, to the experimental data are also shown in Figure 7 for the case of adoption of interface-controlled growth. An inset of Figure 7 also shows the data as Johnson-Mehl-Avrami-Kolmogorov (JMAK)-type 
plots $[\ln (\ln (1 /(1-f)))$ vs $\ln (t)]$, which are strongly non-linear and cannot be fitted with one JMAK exponent. ${ }^{\dagger}$ The specific model presented in the present

${ }^{\dagger}$ JMAK plots of the initial stages of the transformation $(f<0.15)$ give values for the JMAK exponent $n=0.66 \pm 0.05,0.92 \pm 0.04$, and $1.2 \pm 0.1$ at $573 \mathrm{~K}, 613 \mathrm{~K}$, and $653 \mathrm{~K}\left(300{ }^{\circ} \mathrm{C}, 340{ }^{\circ} \mathrm{C}\right.$, and $\left.380{ }^{\circ} \mathrm{C}\right)$, respectively. JMAK exponents between $2 / 3$ and 1 have been interpreted as indicative for growth of plates with finite dimensions. ${ }^{[41]}$ This rather unspecific result, for only the initial stage, is not necessarily incompatible with the current interpretation on the basis of a much more specific kinetic model that is able to describe the whole range of the transformation.

study is well able to describe better (within the experimental error) the transformation curves.

The transformation kinetics model was fitted simultaneously to the experimental data at all temperatures, with $Q$ and $\xi$ as fit parameters. The fitting parameter $Q$ was taken the same at each isothermal temperature, whereas the impingement factor, $\xi$, was set dependent on the isothermal temperature (see Section III-C).
The fit results obtained for the case of adoption of interface-control growth and for the case of adoption of diffusion-controlled growth have been summarized in Table III together with the mean square errors (MSE). The MSE for the set of experimental data, $f_{\exp }$, and the calculated data, $f_{\text {calc }}$, for the fraction of $\zeta$-phase formed at a given temperature, is given by

$$
\mathrm{MSE}=\frac{1}{n} \sum_{i=1}^{n}\left(\frac{f_{\exp }-f_{\text {calc }}}{f_{\exp }}\right)^{2},
$$

where $n$ is the number of data points.

The values obtained by the fitting for $Q$ and $\xi$ do not depend strongly on the values adopted for the pre-exponential factors of growth, i.e., $N_{\text {tot }}$ and $M_{0}$ or $N_{\text {tot }}$ and $D_{0}$, upon increasing/decreasing these parameters by an order of magnitude: practically the same MSE values are obtained (see Table III). Also the consequences of changes of two orders of magnitude are moderate: for $2.1 \times 10^{-20}<N_{\text {tot }}<2.1 \times 10^{-18}, \quad 400<M_{0}<40000$ seconds, and $3.15 \times 10^{-6}<D_{0}<3.15 \times 10^{-4} \mathrm{~m}^{2} \mathrm{~s}^{-1}$. It follows: (1) in case of adopting interface-controlled

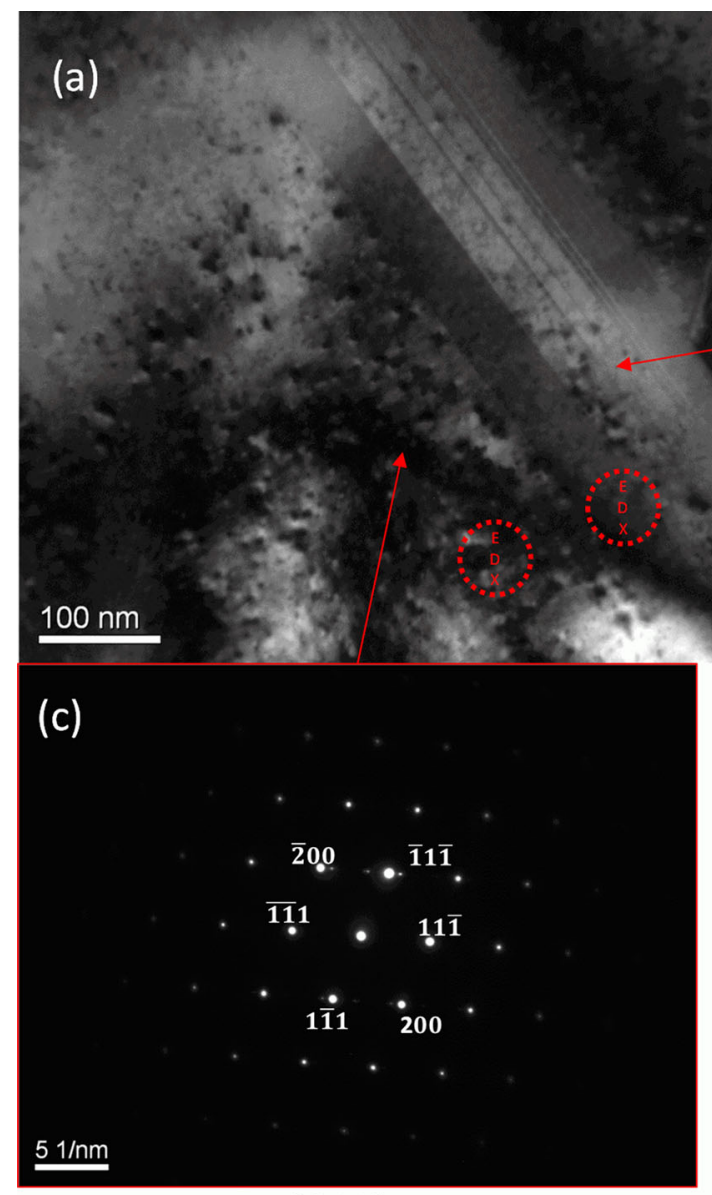

$z=[011] \alpha$

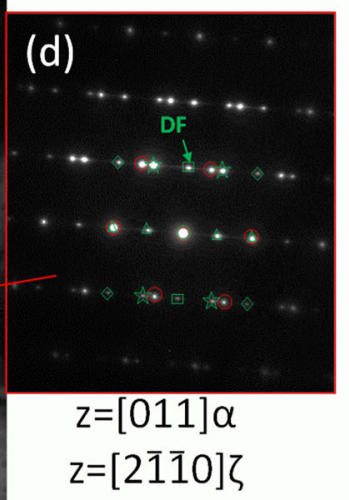

(e)
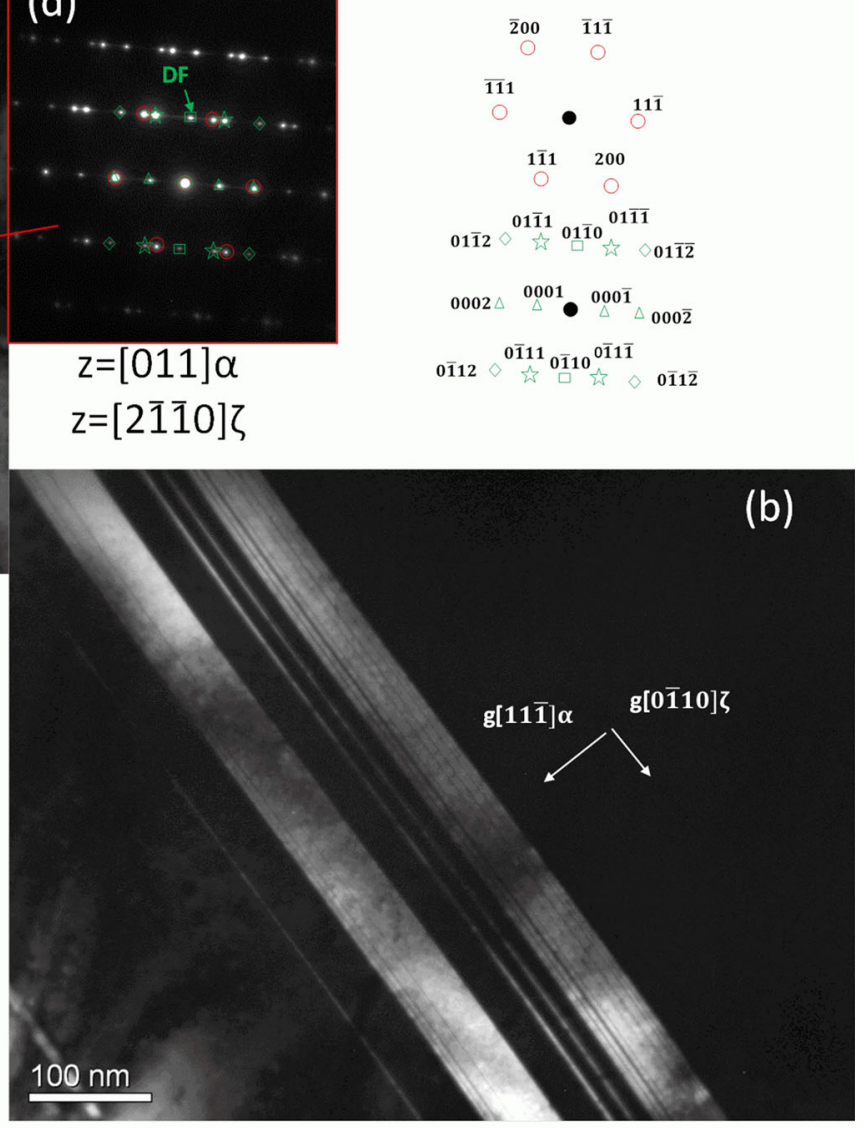

Fig. 6 - (a) Bright-field image of a Cu-Ge sheet specimen aged at $613 \mathrm{~K}\left(340{ }^{\circ} \mathrm{C}\right)$ for 8 days showing stacking faults (here $\zeta$-phase formation has taken place). The locations where EDX analyses were undertaken are shown with circles. (b) Dark-field image (DF) of the same region using the diffraction spot indicated with an arrow in the SADP in $(d)$. (c) SADP taken in the region outside the region of stacking faults. (d) SADP taken within the region of the stacking faults. (e) Schematic representation of the diffraction spots shown in (c) and (d). Top part of figure: diffraction spots of $\alpha-\mathrm{Cu}(\mathrm{Ge})$; bottom part of figure: diffraction spots of $\zeta$-phase. Zone axis: $[011]_{\alpha} /[2 \overline{1} 10]_{\zeta}$. 
growth, the activation energy for growth, $Q_{\mathrm{G}}$, changes only up to $\pm 12 \mathrm{~kJ} \mathrm{~mol}^{-1}$; $\xi$ changes only up to about \pm 15 pct; and MSE is on average $0.8,3.0$, and 5.8 pet at $573 \mathrm{~K}, 613 \mathrm{~K}$, and $653 \mathrm{~K}\left(300{ }^{\circ} \mathrm{C}, 340{ }^{\circ} \mathrm{C}\right.$, and $\left.380^{\circ} \mathrm{C}\right)$, respectively and (2) in case of adopting diffusion-controlled growth, the activation energy for diffusion, $Q_{\mathrm{D}}$, changes up to $\pm 24 \mathrm{~kJ} \mathrm{~mol}^{-1}, \xi$ changes only up to about \pm 20 pct; and MSE (see below) is on average 3.0, 7.2 , and 12.1 pet at $573 \mathrm{~K}, 613 \mathrm{~K}$, and $653 \mathrm{~K}\left(300{ }^{\circ} \mathrm{C}\right.$, $340{ }^{\circ} \mathrm{C}$, and $380{ }^{\circ} \mathrm{C}$ ) respectively. It is concluded that the values obtained by model fitting for $Q$ and $\xi$ are robust.

\section{Interpretation of the impingement parameter $\xi$}

The values of the impingement parameter for anisotropic growth in the present study are higher than the previously reported experimental values, e.g., in order of

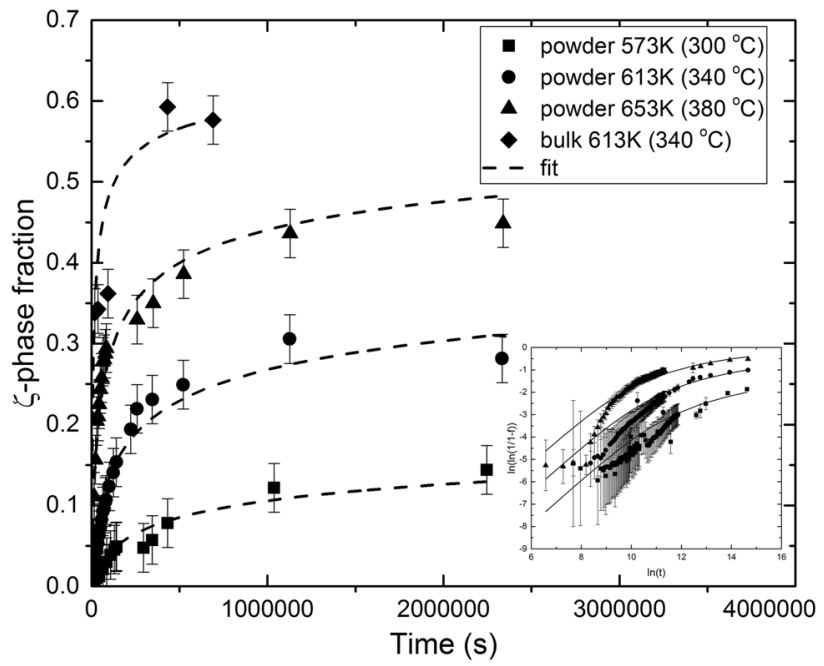

Fig. 7-Development of the $\zeta$-phase fraction in powder and bulk specimens with time at $573 \mathrm{~K}, 613 \mathrm{~K}$, and $653 \mathrm{~K}\left(300{ }^{\circ} \mathrm{C}, 340{ }^{\circ} \mathrm{C}\right.$, and $\left.380^{\circ} \mathrm{C}\right)$. The lines drawn through the data are the results of the fitting of the kinetic model (cf. Eqs. [10a] and [12]) to the data with the adopted site-saturation nucleation mode and the adopted interface-controlled anisotropic growth mode. The obtained values for the fit parameters have been gathered in Table III. The inset shows the "log- $\log$ " plot, $\ln (\ln (1 / 1-f))$ vs $\ln (t),{ }^{[14]}$ of $\zeta$-phase fraction evolution with time. increasing $\xi, \xi=1.35$ for isochronal allotropic transformations in $\mathrm{Co},{ }^{[7]} \xi=1.63$ to 1.67 for polytypic Laves phase transformation in $\mathrm{TiCr}_{2},{ }^{[25]} \xi=1.5$ to 1.7 for diffusion-controlled precipitation in Al-6 pet $\mathrm{Si},{ }^{[39]}$ $\xi=2.0$ for crystallization of $\mathrm{Zr}_{50} \mathrm{Al}_{10} \mathrm{Ni}_{40}$ metal glass, ${ }^{[42]}$ and $\xi=2.59$ for diffusion-controlled precipitation in Al-1 pet Si. ${ }^{[37]}$ Several authors ${ }^{[38,43]}$ have thus suggested, on phenomenological basis, that $0<\xi<2$, but there is no generally valid theoretical justification of an upper limit $(\xi=2)$ for the impingement parameter.

In the present work, long and narrow particles form (the $\zeta$-phase plates are as long as the grain size (see Figure 3 ) and as narrow as some tens of nanometers (see Figure 6), i.e., the aspect ratio equals $\sim 2 \times 10^{-4}$ to $4 \times 10^{-4}$ ), which is consistent with the specific site-saturation model used in this work. ${ }^{[44]}$ The extremely anisotropic growth is obviously associated with highly effective blocking and thus, with relatively high values of $\xi$, see also Reference 45 .

The maximum $\zeta$-phase fraction that was reached in the present study, at all temperatures, is well below the expected, theoretical, fraction by applying the lever rule (cf. Section III-C). Previous Monte-Carlo (MC) simulations in Reference 44, have already shown that transformation, subject to anisotropic growth and "hard" impingement, effectively stops before being completed such that the fraction transformed reaches an upper limit lower than the theoretically expected one. Phase transformations with experimentally observed saturation levels lower than the thermodynamically predicted ones have also been reported for steels in Reference 46.

From a purely mathematical point of view it is obvious that the occurrence of saturation levels smaller than the theoretical end value intrinsically involves the occurrence of high values of the impingement parameter. Indeed, performing model fitting to the transformation kinetics with adopting the experimentally observed low values of the saturation, end level, leads to values of the impingement parameter $<2$ (at all temperatures). However, there is no ground to expect the theoretical, thermodynamic saturation, end level, of the transformation to be invalid. Therefore, in this work the theoretical saturation, end level, is adopted and the

Table III. Values Determined for the Fit Parameters $\left(Q_{\mathrm{G}}=112.0 \pm 2.8 \mathrm{~kJ} \mathrm{~mol}^{-1}, Q_{\mathrm{D}}=94.0 \pm 5.5 \mathrm{~kJ} \mathrm{~mol}^{-1}\right)$ Adopting Site-Saturation Nucleation and Either Interface-Controlled Growth or Diffusion-Controlled Growth for Fitting the Experimental Data with the Kinetic Model

Fit Parameter

\begin{tabular}{|c|c|c|c|c|}
\hline Temperature $\left[\mathrm{K}\left({ }^{\circ} \mathrm{C}\right)\right]$ & $Q\left(\mathrm{~kJ} \mathrm{~mol}^{-1}\right)$ & $\xi$ & $\langle\mathrm{MSE}\rangle(\mathrm{Pct})$ & $R^{2}$ \\
\hline \multicolumn{5}{|c|}{ Powder specimens: interface-controlled growth } \\
\hline $573(300)$ & $Q_{\mathrm{G}}=112.0 \pm 2.8$ & $21.0 \pm 2.9$ & 0.6 & \multirow[t]{3}{*}{0.9750} \\
\hline $613(340)$ & & $8.7 \pm 0.6$ & 2.9 & \\
\hline $653(380)$ & & $5.3 \pm 0.3$ & 5.8 & \\
\hline \multicolumn{5}{|c|}{ Powder specimens: diffusion-controlled growth } \\
\hline $573(300)$ & $Q_{\mathrm{D}}=94.0 \pm 5.5$ & $11.0 \pm 3.0$ & 2.9 & \multirow[t]{3}{*}{0.9538} \\
\hline $613(340)$ & & $3.1 \pm 0.5$ & 7.2 & \\
\hline $653(380)$ & & $2.3 \pm 0.4$ & 12.0 & \\
\hline \multicolumn{5}{|c|}{ Bulk specimens: interface-controlled growth } \\
\hline $613(340)$ & $Q_{\mathrm{G}}=98 \pm 27$ & $1.8 \pm 0.3$ & 21 & 0.9314 \\
\hline
\end{tabular}


thus obtained high values of the impingement parameter are believed to be genuine and characteristic for the present case of transformation with extremely anisotropic growth.

Finally, the values of the impingement parameter and the saturation, end level, have little consequence for the conclusions drawn for the dominant mechanism that controls the kinetics of the phase transformation, as discussed in the following.

\section{Dominant mechanisms of the transformation}

The best fit, i.e., the smallest mean square error $(M S E)$, is obtained adopting the interface-controlled growth mode, as compared to the diffusion-controlled growth mode. The $M S E$ values for diffusion-controlled growth, at each temperature, are at least twice larger than those for interface-controlled growth. The difference in the activation energy values obtained for the two growth modes is larger than 2 standard deviations.

The deduced occurrence of interface-controlled growth, in the fashion that the $\zeta$-phase formation in supersaturated $\alpha-\mathrm{Cu}(\mathrm{Ge})$ is controlled by glide of SPs at the product/parent phase interface, can be substantiated by the following additional observations and considerations:

(a) It was shown in Section IV-A that the SF regions exhibit a slightly higher Ge content than the matrix, prior to $\zeta$-phase formation at these locations: Ge segregation at SFs precedes the $\zeta$-phase formation. This is also in agreement with the JMAK plots of the initial stages of the transformation (see above). Enrichment of $\mathrm{Si}$ at SFs in $\alpha-\mathrm{Cu}(\mathrm{Si})$ (the $\mathrm{Cu}-\mathrm{Si}$ system is similar to the $\mathrm{Cu}-\mathrm{Ge}$ system) was observed to be relatively rapid (i.e., after only 15 minutes of isothermal annealing of a supersaturated $\mathrm{Cu}-\mathrm{Si}$ solid solution of 7.15 at. pct $\mathrm{Si}$ at $548 \mathrm{~K}\left(275^{\circ} \mathrm{C}\right)$, an enrichment of 2.28 at. pct of $\mathrm{Si}$ (additional to the matrix composition of 7.15 at. pet $\mathrm{Si}$ ) was observed at the SFs). ${ }^{[40]}$

(b) The thermodynamically prescribed compositional difference of the $\alpha-\mathrm{Cu}(\mathrm{Ge})$ matrix and the $\zeta$-phase ( $c f$. the phase diagram; see Figure 1) can be realized by diffusion in the matrix in short time. Using the diffusion coefficient for Ge from Reference $34\left(D_{0}=0.397, Q_{\mathrm{D}}=187 \mathrm{~kJ} \mathrm{~mol}^{-1}\right)$, the time required for Ge atoms to cover a length of $\sim 2 \mathrm{~nm}$ (of the order of the extent of the solute depletion zone; see above) is calculated to be approximately 50, 500, and 5000 seconds at $653 \mathrm{~K}, 613 \mathrm{~K}$, and $573 \mathrm{~K}\left(380{ }^{\circ} \mathrm{C}, 340{ }^{\circ} \mathrm{C}\right.$, and $300{ }^{\circ} \mathrm{C}$ ), respectively, which times are very much shorter than the observed transformation times (of up to 4 weeks annealing). Hence, diffusion of $\mathrm{Ge}$ (in $\alpha-\mathrm{Cu}(\mathrm{Ge})$ ) is most likely not a transformation-rate determining process.

(c) If yet a diffusion-controlled growth mode is adopted in the fitting, the value obtained for the activation energy for diffusion of $\mathrm{Ge}$ in $\mathrm{Cu}$ $\left(94.0 \pm 5.5 \mathrm{~kJ} \mathrm{~mol}^{-1}\right.$; see Table III), is distinctly lower than the literature value $\left(185 \mathrm{~kJ} \mathrm{~mol}^{-1}\right.$ for diffusion of $\mathrm{Ge}$ through pure $\mathrm{Cu}$ single crys- tals ${ }^{[34,35]}$, which is compatible with the above conclusion that diffusion-controlled growth is not rate determining. Adopting an interface-controlled growth mode in the fitting, the value obtained for the activation energy for dislocation glide hindered by obstacle resistance is $112.0 \pm 2.8 \mathrm{~kJ} \mathrm{~mol}^{-1}$ (see Table III), which is well compatible with the reported values for the activation energy for glide of dislocations in $\mathrm{Cu}-\mathrm{Ge}$ alloys (Ge content in the range of 0.5 to 3.3. at. pct), i.e., 109 to $130 \mathrm{~kJ} \mathrm{~mol}^{-1}$. [47]

(d) The activation energy of overcoming obstacles by gliding dislocations, without the aid of external stress, can be given by $Q=\beta N_{A} \mu_{0}|b|^{3}$, where $N_{\mathrm{A}}$ is the Avogadro constant; $\mu_{0}$ is the shear modulus (due to shortage of data for $\mathrm{Cu}(\mathrm{Ge})$, here taken as for pure $\mathrm{Cu}$ at $300 \mathrm{~K}\left(27^{\circ} \mathrm{C}\right)\left(=4.21 \times 10^{10} \mathrm{~N}\right.$ $\left.\left.\mathrm{m}^{2}\right)^{[32]}\right) ;|b|$ is the length of the Burgers vector $\left(\sim 2.5 \times 10^{-10} \mathrm{~m}\right)$; and $\beta$ is a constant that defines the magnitude of the resistance to glide. ${ }^{[32]}$ From the here obtained value for the activation energy for glide of dislocations, $112.0 \pm 2.8 \mathrm{~kJ} \mathrm{~mol}^{-1}$, the constant $\beta$ was then found to be equal to $\sim 0.3$ which indicates a medium resistance to glide, as typical for fcc metals (which have relatively low lattice resistance), and as generally due to defects or small precipitates. ${ }^{[32]}$

It is observed that the XRD technique applied in this work allowed the first detection of the developing product phase after times increasing with isothermal annealing temperature (see beginning of Section IV). This is just a consequence of the nucleation density being larger at lower temperature; see Section III-B-1. There is of course competition with the thermally activated growth, becoming slower with decreasing temperature, but apparently the athermal nucleation process dominates the value of the seeming "incubation time." Do note that in the present interpretation/model there is no real incubation time. The apparent incubation time is caused by the lack of sensitivity of the measurement technique (XRD) to respond to the smallest amount of new phase formed.

The impingement parameter decreases with increasing isothermal annealing temperature (see Table III). This can (also; see above) be interpreted as the consequence of a nucleation density becoming smaller with increasing temperature, thereby promoting at higher temperature less precipitates and correspondingly less severe impingement.

A limited number of bulk specimens (sheet material of supersaturated $\mathrm{Cu}(\mathrm{Ge})$ with 10.8 at. pct $\mathrm{Ge}$; $c f$. Section II-A) were isothermally annealed at $613 \mathrm{~K}$ $\left(340{ }^{\circ} \mathrm{C}\right)$ in order to investigate whether the amount of $\zeta$-phase in these specimens deviates from that of the powder specimens, for similar annealing times. It was observed that relatively high $\zeta$-phase fractions were obtained for the bulk specimens after (only) 8 days of isothermal annealing at $613 \mathrm{~K}\left(340{ }^{\circ} \mathrm{C}\right)$, see Figure 7.

Fitting of the kinetic model to the experimental data obtained for the bulk specimens $(D=50 \mu \mathrm{m} ; c f$. Section II-A and thus $N_{\text {tot }}=1.9 \times 10^{18} ; \quad c f$. 
Equation [5] showed that the value obtained for the activation energy for dislocation glide, $98 \pm 27 \mathrm{~kJ} \mathrm{~mol}^{-1}$ (see footnote ${ }^{\ddagger}$ ), is compatible (within

\footnotetext{
${ }^{\ddagger}$ Note that the larger uncertainty in the results for the bulk specimens, as compared to the powder specimens (cf. Table III), is a consequence of larger scatter in the X-ray data (less good crystal statistics than for the powder specimens; cf. Sections II-A and II-B).
}

experimental accuracy) with data for the activation energy for the glide of dislocations (109 to $130 \mathrm{~kJ} \mathrm{~mol}^{-1[47]}$, as holds for the powder specimens.

A striking difference of the bulk and the powder material concerns the maximum (saturation) level of the transformation, being larger for the bulk specimen. This result suggests $(c f$. discussion for the powder specimens in Section IV-B-1.) the occurrence of less severe impingent for the bulk specimens, as follows. The total number of pre-existing SPs (i.e., nucleation sites) is inversely proportional to the second power of the grain size (Eq. [5]). Hence, the bulk specimens (grain size of $50 \mu \mathrm{m}$ ) can be expected to exhibit a much lower nucleation density than the powder specimens, for the same annealing temperature $\left(c f\right.$. data for $613 \mathrm{~K}\left(340{ }^{\circ} \mathrm{C}\right)$ given in Figure 7). This effect leads to less pronounced impingement in case of the bulk specimens (the role of temperature is demonstrated and discussed for the powder specimens in Section IV-B-1).

\section{CONCLUSIONS}

1. The transformation kinetics of the $\zeta$-phase formation from supersaturated $\mathrm{Cu}(\mathrm{Ge})$ solid solutions can be described on the basis of a modular transformation model adopting a (heterogeneous) site-saturation nucleation mode and a strongly anisotropic interface-controlled growth mode.

2. Segregation of Ge in the SFs occurs, before formation of the $\zeta$-phase takes place.

3. The associated diffusion of $\mathrm{Ge}$ in the alpha- $\mathrm{Cu}(\mathrm{Ge})$ matrix does not control the transformation kinetics.

4. The obtained value of the activation energy is well compatible with thermally activated glide of Shockley partial dislocations.

5. The transformation kinetics is considerably faster in the bulk (sheet) specimens than in the powder specimens due to a lesser impingement (coarse grained microstructure) and a more copious nucleation (larger dislocation density), while the rate-controlling mechanism (glide of SPs) remains the same.

\section{ACKNOWLEDGMENTS}

Open access funding provided by Max Planck Society. The authors would like to thank Mr. P. Kreß, Mr. T. Meisner, and Mr. A. Weible for help in materials' preparation, Mr. S. Hammoud and Mr. G. Werner for ICP-OES analysis, and Mr. D. Lang for TEM-speci- men preparation (all with the Max Planck Institute for Intelligent Systems).

\section{OPEN ACCESS}

This article is distributed under the terms of the Creative Commons Attribution 4.0 International License (http://creativecommons.org/licenses/by/4.0/), which permits unrestricted use, distribution, and reproduction in any medium, provided you give appropriate credit to the original author(s) and the source, provide a link to the Creative Commons license, and indicate if changes were made.

\section{REFERENCES}

1. P.S. Kotval and R.W.K. Honeycombe: Acta Metall., 1968, vol. 16, pp. 597-607.

2. P.J. Moroz, R. Taggart, and D.H. Polonis: J. Mater. Sci., 1987, vol. 22, pp. 839-52.

3. Y. Ruan, F. Dai, and B. Wei: Chin. Sci. Bull., 2007, vol. 52, pp. $2630-35$.

4. D.B. Williams and C.B. Carter: Electron Microscopy: A Textbook for Materials Science, Springer US, Boston, 2009

5. K.T. Moore, W.C. Johnson, J.M. Howe, H.I. Aaronson, and D.R. Veblen: Acta Mater., 2002, vol. 50, pp. 943-56.

6. S.I. Wright and M.M. Nowell: Electron Backscatter Diffraction in Materials Science, J.A. Schwartz, M. Kumar, L.B. Adams, and P.D. Field, eds., Springer US, Boston, 2009, pp. 329-37.

7. R. Bauer, E.A. Jagle, W. Baumann, and E.J. Mittemeijer: Philos. Mag., 2011, vol. 91, pp. 437-57.

8. R.W. Olesinski and G.J. Abbaschian: Bull. Alloy Phase Diagr., 1986, vol. 7, pp. 28-35.

9. P.J. Moroz, R. Taggart, and D.H. Polonis: Mater. Sci. Eng., 1986, vol. 79, pp. 201-10.

10. A.J. McAlister: J. Phase Equilib., 1987, vol. 8, pp. 526-33.

11. K.T. Moore and J.M. Howe: Acta Mater., 2000, vol. 48, pp. 4083-98.

12. C. Laird and H.I. Aaronson: Acta Metall., 1969, vol. 17, pp. 505-19.

13. K.R. Kinsman, H.I. Aaronson, and E. Eichen: Metall. Trans., 1971, vol. 2, pp. 1041-54.

14. E.J. Mittemeijer: Fundamentals of Materials Science, Springer, Berlin, 2011, pp. 371-461.

15. E.J. Mittemeijer and F. Sommer: Z. Metallkd., 2002, vol. 93, pp. $352-61$.

16. E.J. Mittemeijer and F. Sommer: Int. J. Mater. Res., 2011, vol. 102 , pp. $784-95$

17. H.P. Klug and L.E. Alexander: X-Ray Diffraction Procedures: For Polycrystalline and Amorphous Materials, 2nd ed., Wiley, New York, 1974, pp. 534-35.

18. G. Cliff and G.W. Lorimer: J. Microsc., 1975, vol. 103, pp. 203-07.

19. A.H. Cottrell: The Mechanical Properties of Matter, Wiley, New York, 1964

20. T. Waitz and H.P. Karnthaler: Acta Mater., 1997, vol. 45, pp. 837-47.

21. G.B. Olson and M. Cohen: Metall. Trans. A, 1976, vol. 7A, pp. 1897-1904.

22. F. Liu, F. Sommer, C. Bos, and E.J. Mittemeijer: Int. Mater. Rev., 2007, vol. 52, pp. $193-212$

23. F. Liu, F. Sommer, and E.J. Mittemeijer: J. Mater. Sci., 2004, vol. 39, pp. 1621-34.

24. B. Rheingans and E.J. Mittemeijer: JOM, 2013, vol. 65, pp. $1145-54$

25. W. Baumann, A. Leineweber, and E.J. Mittemeije: Intermetallics, 2011, vol. 19 , pp. 526-35.

26. G.B. Olson and M. Cohen: Metall. Trans. A, 1976, vol. 7A, pp. $1915-23$. 
27. M.F. Lin, G.B. Olson, and M. Cohen: Metall. Trans. A, 1992, vol. 23A, pp. 2987-98.

28. T.B. Massalski and B. Gockayne: Acta Metall., 1959, vol. 7, pp. 762-68

29. J.O. Andersson, T. Helander, L. Höglund, P. Shi, and B. Sundman: Calphad, 2002, vol. 26, pp. 273-312.

30. P.C.J. Gallagher: Metall. Trans., 1970, vol. 1, pp. 2429-61.

31. L. Rémy, A. Pineau, and B. Thomas: Mater. Sci. Eng., 1978, vol. 36, pp. 47-63.

32. H.J. Frost and M.S. Ashby: Deformation-Mechanism Maps: The Plasticity and Creep of Metals and Ceramics, Pergamon Press, Oxford, 1974, pp. 7-25.

33. E. Orowan: Proc. Phys. Soc., 1940, vol. 52, pp. 8-22.

34. A.D. LeClaire and G. Neumann: Landolt-Börnstein-Group III Condensed Matter, vol. 26, H. Mehrer, ed., Springer, Berlin, 1990, pp. $136-49$.

35. F.D. Reinke and C.E. Dahlstro: Philos. Mag., 1970, vol. 22, pp. 57-62.

36. M.J. Starink: J. Mater. Sci., 2001, vol. 36, pp. 4433 41.
37. M. Tomellini, M. Fanfoni, Ph. Rev. B, 2008, 78, pp. 014206-1-014206-10.

38. M. Hilliert: Acta Metall., 1959, vol. 7, pp. 653-58.

39. M.J. Starink and A.M. Zahra: Thermochim. Acta, 1997, vol. 292, pp. $159-68$.

40. B.G. Mendis, I.P. Jones, and R.E. Smallman: J. Electron. Microsc., 2004, vol. 53, pp. 311-23.

41. J.W. Christian: The Theory of Transformations in Metals and Alloys, Pergamon Press, Oxford, 2002, pp. 529-52.

42. F. Liu, H. Nitsche, F. Sommer, and E.J. Mittemeijer: Acta Mater., 2010, vol. 58, pp. 6542-53.

43. T. Takashi and S.-I. Tanaka: Acta Mater., 1997, vol. 45, pp. 3341-47.

44. B.J. Kooi: Phys. Rev. B, 2006, vol. 73, pp. 054103-1-13.

45. M.C. Weinberg and D.P. Birnie, III: J. Non-Cryst. Solids, 1996, vol. 202, pp. 290-96.

46. H.I. Aaronson, W.T. Reynolds, Jr., and G.R. Purdy: Metall. Mater. Trans. A, 2006, vol. 37A, pp. 1731-45.

47. T.H. Wille, W. Gieseke, and C.H. Schwink: Acta Metall., 1987, vol. 35, pp. 2679-93. 